\title{
Probiotic Lactobacillus sp. with bioremediation potential of toxic heavy metals
}

\author{
Sangita Ahmed ${ }^{1 *}$, Md Rafiqul Islam ${ }^{1}$, Jannatul Ferdousi ${ }^{1}$ and Tabassum Samia Iqbal ${ }^{1}$ \\ ${ }^{I}$ Department of Microbiology, University of Dhaka, Dhaka-1000, Bangladesh
}

\begin{abstract}
Pollution of the environment and food with toxic heavy metals is being intensified in Bangladesh with industrial development. Consumption of foods and water contaminated with heavy metals imposes threat to human health. Aiming to find a solution to this problem, the present study focuses on probiotic Lactobacillus spp. with potential to remove heavy metals from environment as well as human body. A total of three Lactobacillus spp were isolated from curd samples and were identified based on their morphological and biochemical properties. These isolates were tolerant to low $\mathrm{pH}$ and bile salt which aids in their application in human gut. All isolates could tolerate $600 \mathrm{ppm}$ chromium, $400 \mathrm{ppm}$ lead, $400 \mathrm{ppm}$ copper and $400 \mathrm{ppm}$ zinc. The heavy metal tolerant Lactobacillus spp were also multi drug resistant and showed $\mathbf{1 0 0 \%}$ resistance to Azithromycin, Cloxacillin, Gentamicin, Vancomycin, Streptomycin, Nalidixic acid, Trimethoprim-Sulfamethoxazole and Penicillin, while $100 \%$ sensitivity was observed to Imipenem.
\end{abstract}

Key words: Lactobacillus, heavy metal, antibiotic

Heavy metal contamination is a serious problem from both human health and environmental perspective. The increasing contamination of food and water with a range of heavy metals, such as lead, cadmium, arsenic, chromium, and mercury and their exposure to populations remains a major concern in Bangladesh in recent years ${ }^{1}$. These hazardous, toxic heavy metals adversely affect human health by bioconcentration, bioaccumulation and biomagnification phenomenon. In children, exposure to high concentration of heavy metals like cadmium, lead, chromium, mercury can cause potentially permanent learning and behavior disorders $^{2}$. In adults as well as in children heavy metals have deleterious effects on heart, bones, intestines, kidneys, reproductive and nervous systems and leads to death in extreme cases $^{2}$. While many developed countries have taken some actions to monitor and reduce the problem of heavy metal contamination, it remains neglected in Bangladesh. It is worsening with increasing urbanization and industrial development. Additionally, available conventional methods (precipitation, flocculation, ion exchange, and membrane filtration) for removal of heavy metals from the environment are sometimes inefficient and expensive for practical large-scale use, especially for developing countries like Bangladesh ${ }^{3}$. Therefore it is necessary to seek alternative solutions for reducing the load of toxic heavy metals from the environment and thereby protecting human.

Recently, ability of probiotic bacteria, such as Lactobacillus sp., to bind and detoxify toxic heavy metals has generated much attention globally ${ }^{4-9}$. Moreover, with evidences of safe application in human, Lactobacillus becomes an attractive candidate for preventing absorption of metals into the human body $^{6}$. Use of Lactobacilli also offers some advantages, such as, immediate application, no requirement for expensive technology or infrastructure setup etc ${ }^{7,9}$. Therefore, this bacterium can also be used as a tool to reduce heavy-metal toxicity from environment ${ }^{7,9}$. This study aims to isolate heavy metal-resistant Lactobacillus sp. from yogurt samples, which could potentially be used for removing heavy metals from environment as well as human health.

To isolate Lactobacillus sp. five different curd samples were collected from shop and $0.1 \mathrm{ml}$ from each curd sample was spread on to MRS (De Man, Rogosa and Sharpe, Difco Laboratories, Detroit, MI, USA) agar medium, a selective medium for Lactobacillus. Following incubation at $37^{\circ} \mathrm{C}$ for 24 hours isolated colonies were selected for further characterization. Presumptive Lactobacillus spp, were identified using microscopic analysis and biochemical tests as suggested by the Bergey's Manual of Bacteriology ${ }^{10}$.

To determine the maximum tolerance of the Lactobacillus isolates to heavy metals, each isolate was grown at $37^{\circ} \mathrm{C}$ for 48 hours in $5 \mathrm{ml}$ MRS broth medium in screw capped tubes supplemented with different concentrations of each metal (lead, chromium, copper or zinc). Stock solutions of lead as $0.5 \mathrm{M}$ $\mathrm{Pb}\left(\mathrm{NO}_{3}\right)_{2}$ and chromium as $4.0 \mathrm{M} \mathrm{K}_{2} \mathrm{Cr}_{2} \mathrm{O}_{7}$ were prepared and filter sterilized. From each stock solution, appropriate amount was added in MRS broth to dissolve lead in the concentration ranging from 100 to $500 \mathrm{ppm}$ and chromium ranging from 100 to $600 \mathrm{ppm}$. Analysis of resistance to copper and zinc was also determined in a similar way. Copper was added to MRS broth as $\mathrm{CuSO}_{4} \cdot 5 \mathrm{H}_{2} \mathrm{O}(100-500 \mathrm{ppm})$ and zinc was added as $\mathrm{ZnSO}_{4} .7 \mathrm{H}_{2} \mathrm{O}$ (100-500 ppm). Following incubation at $37^{\circ} \mathrm{C}$ for 48 hours,

Corresponding author*

Dr Sangita Ahmed, Associate Professor, 'Department of Microbiology, University of Dhaka, Dhaka-1000, Bangladesh. Email: sangita@du.ac.bd 
growth of each bacterial culture was measured by measuring absorbance at $600 \mathrm{~nm}$.

The acid-tolerance of the Lactobacillus isolates was investigated following the method described by Bhakta et al., (2012) ${ }^{9}$. Briefly, fresh culture of Lactobacillus sp. grown in MRS broth was centrifuged at $13000 \mathrm{~g}$ for $5 \mathrm{~min}$ and the cell pellet was washed twice with normal saline. The cell pellet was then suspended in sterile phosphate-buffered saline (PBS) adjusted to $\mathrm{pH}$ 1.0, 1.5, 2.0, 2.5 or 3.0 (using $10 \mathrm{M} \mathrm{HCl}$ ) and incubated at $37^{\circ} \mathrm{C}$ for $2 \mathrm{~h}$. Following incubation, $0.1 \mathrm{ml}$ bacterial culture in PBS was inoculated on MRS agar medium and tolerance of the isolates was assessed in terms of their growth after $48 \mathrm{~h}$ incubation at $37^{\circ} \mathrm{C}$.

Bile-tolerance of the Lactobacillus isolates was studied using the method described by Bhakta et al., (2012) $)^{9}$. Each isolate was grown at $37^{\circ} \mathrm{C}$ for $24 \mathrm{~h}$ in MRS broth supplemented with bile salt (Sigma-Aldrich, Germany) at concentrations of 1000, 2000, 3000, $4000,5000,6000,7000$ and $8000 \mathrm{mg} / \mathrm{l})$. After $48 \mathrm{~h}$ incubation at $37^{\circ} \mathrm{C}$, the growth of isolates was recorded by measuring absorbance at $600 \mathrm{~nm}$.

Bacterial susceptibility to anti-microbial agent was determined in vitro by standardized agar-disc diffusion method known as the Kirby Bauer method using commercial antibiotic discs (Oxoid, $\mathrm{UK})^{11}$. Antibiotics and disc potencies used were Penicillin G (10 $\mu \mathrm{g})$, Chloramphenicol $(30 \mu \mathrm{g})$, Azithromycin $(15 \mu \mathrm{g})$, Cloxacillin (5 $\mu \mathrm{g})$, Gentamicin $(10 \mu \mathrm{g})$, Vancomycin $(30 \mu \mathrm{g})$, Streptomycin (15 $\mu \mathrm{g})$, Nalidixic acid (30 $\mu \mathrm{g})$, Trimethoprim-Sulfamethoxazole (25 $\mu \mathrm{g})$ and Imipenem $(10 \mu \mathrm{g})$.

Based on colony morphology on MRS agar, Gram staining and catalase test three presumptive Lactobacillus spp. were isolated from five different curd samples (Figure 1). Further identification at species level needs to be carried out by $16 \mathrm{~s}$ rRNA sequencing.

The Lactobacillus isolates were investigated for their tolerance to different concentrations of heavy metals chromium, lead, copper and zinc. All isolates were able to grow at $600 \mathrm{ppm}$ concentration of chromium and could tolerate $500 \mathrm{ppm}$ concentration of lead, copper, and zinc (Figure 2). This data indicate that these isolates can easily survive in high heavy metal contaminated environment and they might be useful as potential agent for heavy metal bioremediation purpose. However, with increasing concentration of each heavy metal, growth of each isolate decreased. The slower growth rate might be because of the fact that the Lactobacillus spp. need to spend more energy on activation of mechanisms and pathways that allow tolerance of the metals.

Human intestine and stomach is characterized by high acidity and high concentration of bile salts. Therefore acid- and biletolerant abilities are the two primary important criteria for the establishment of any bacterium into the human intestine and stomach (Hyronimus et al. 2000). All three Lactobacillus isolates sp. obtained in this study were found to tolerate up to $8000 \mathrm{mg} /$ $\mathrm{L}$ bile salt (Figure 3 ). None of them grew at $\mathrm{pH} 1.0$, while only isolate 1 was able to grow at $\mathrm{pH} 2.0$ and $\mathrm{pH} 3.0$. All isolates showed best growth at $\mathrm{pH} 2.5$ (Table 1). These observations suggest that these isolates are perfectly suited for administration in human gut for detoxification of heavy metals, of which isolate 1 possesses a wider $\mathrm{pH}$ range for growth compared to the other two.

Several studies suggest that antibiotic and heavy metal resistance genes are often encoded together on the same plasmid ${ }^{13,14}$. Therefore, the heavy metal tolerant Lactobacillus isolates were tested for their antibiotic resistance profile. Investigations revealed that all three isolates were highly resistant to commonly used antibiotics with some exception. All isolates were sensitive to Imipenem only and were resistant to the other antibiotics tested (Azithromycin, Cloxacillin, Gentamicin, Vancomycin, Streptomycin, Nalidixic acid, Trimethoprim-Sulfamethoxazole and Penicillin) in varying degrees (Table 2). Isolate 2 showed more resistance to the antibiotics than the other two isolates. Similar
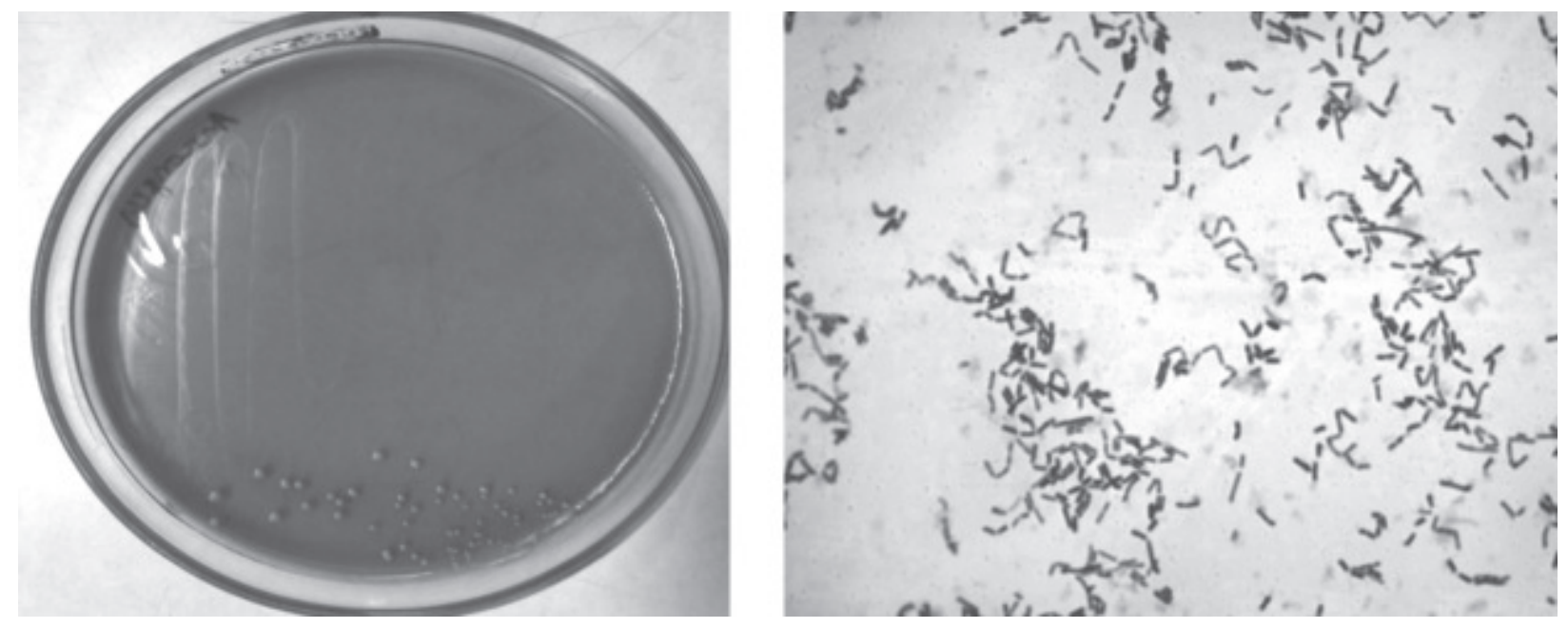

Figure 1. Identification of Lactobacillus sp. based on (a) growth on MRS agar and (b) Gram staining 
Probiotic Lactobacillus sp. with bioremediation potential of toxic heavy metals.
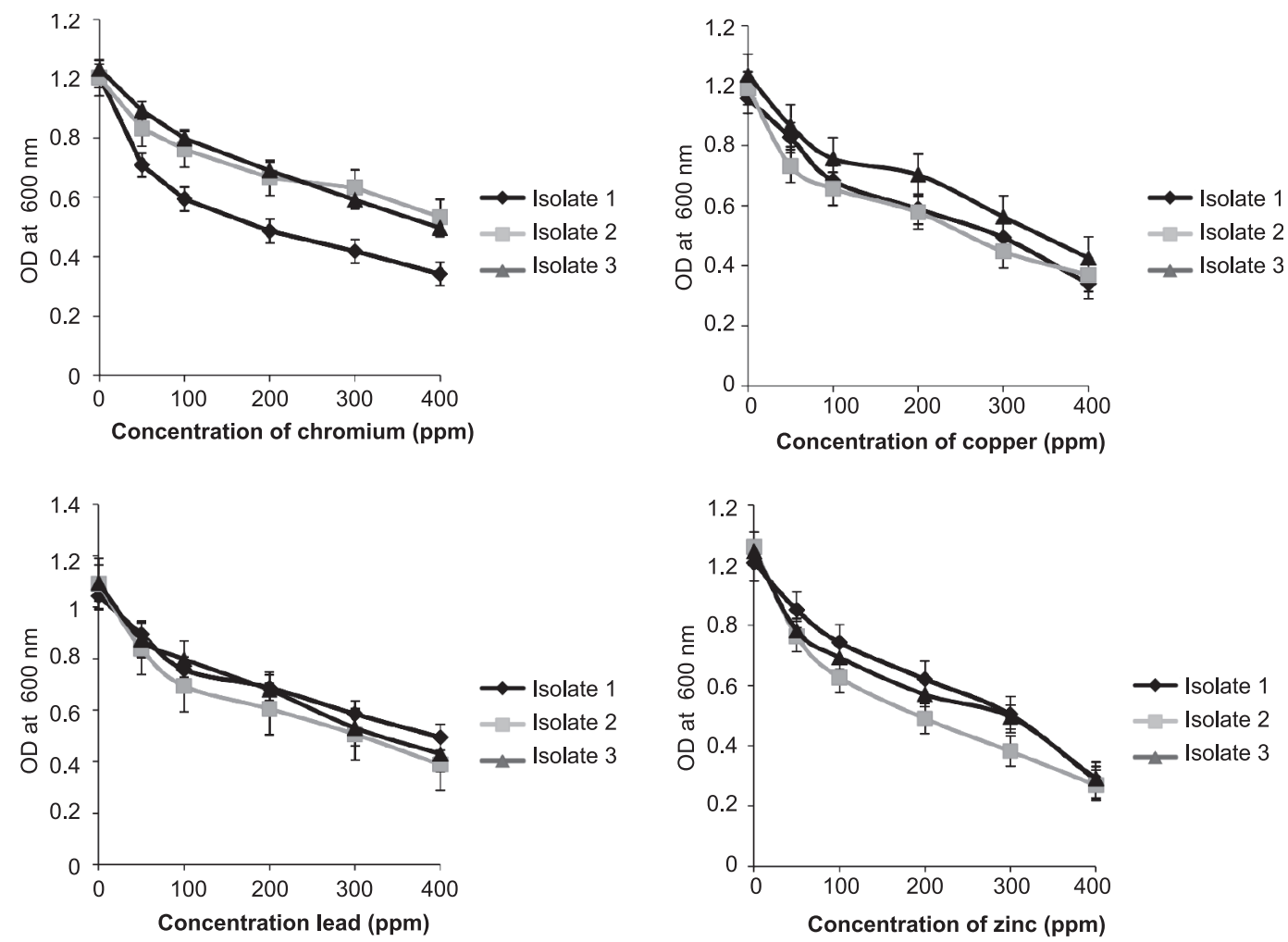

Figure 2. Tolerance of the Lactobacillus isolates to different heavy metals

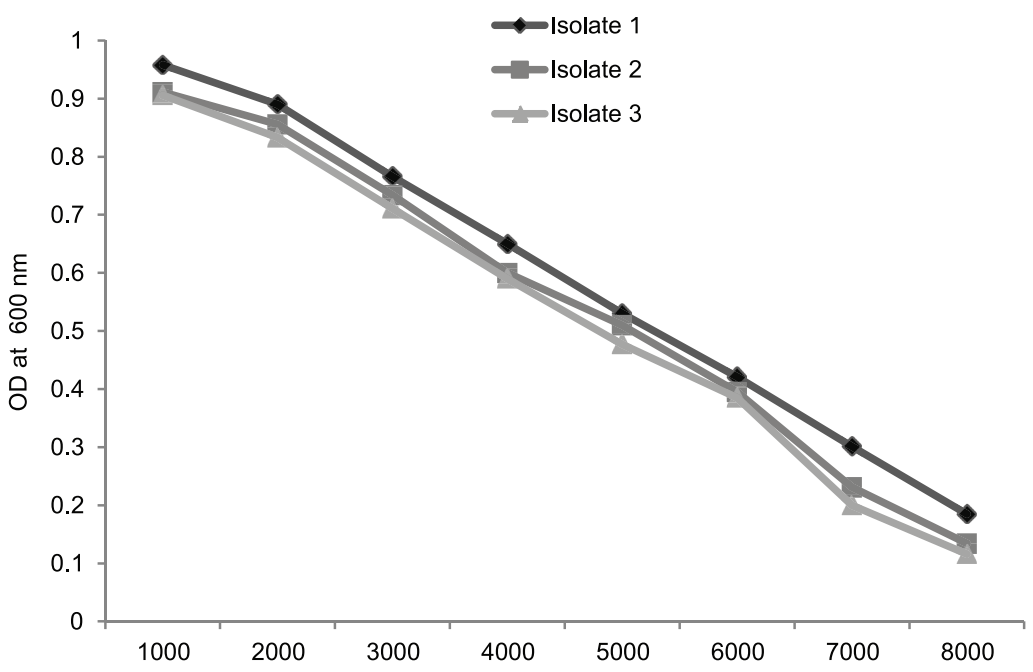

Figure 3. Bile salt tolerance of the Lactobacillus isolates

Table 1. Acid tolerance of Lactobacillus isolates

\begin{tabular}{lccc}
\hline pH value & \multicolumn{3}{c}{ Growth of isolates } \\
\cline { 2 - 4 } & Isolate 1 & Isolate 2 & Isolate 3 \\
\hline 1 & - & - & - \\
1.5 & + & - & - \\
2.0 & ++ & ++ & + \\
2.5 & +++ & +++ & +++ \\
3.0 & + & - & - \\
\hline
\end{tabular}

-: No growth, +: Slight growth; ++: Moderate growth; +++: Confluent growth 
Table 2. Antibiotic resistance pattern of the Lactobacillus isolates

\begin{tabular}{lllc}
\hline Antibiotics & & Isolates & \\
\cline { 2 - 4 } & \multicolumn{1}{c}{1} & 2 & Resistant \\
\hline Azithromycin $(15 \mu \mathrm{g})$ & Resistant & Resistant & Intermediate sensitive \\
Chloramphenicol $(30 \mu \mathrm{g})$ & Intermediate sensitive & Resistant & Resistant \\
Cloxacillin $(5 \mu \mathrm{g})$ & Resistant & Resistant & Resistant \\
Streptomycin $(15 \mu \mathrm{g})$ & Resistant & Resistant & Resistant \\
Gentamycin $(10 \mu \mathrm{g})$ & Resistant & Sensitive & Sensitive \\
Imipenem $(10 \mu \mathrm{g})$ & Sensitive & Resistant & Resistant \\
Vancomycin $(30 \mu \mathrm{g})$ & Resistant & Resistant & Resistant \\
Nalidixic acid $(30 \mu \mathrm{g})$ & Resistant & Resistant & Resistant \\
Trimethoprim-sulfamethoxazole $(25 \mu \mathrm{g})$ & Resistant & Resistant & Resistant \\
Penicillin-G $(10 \mu \mathrm{g})$ & Resistant & Resistant & Intermediate sensitive \\
Tetracycline $(30 \mu \mathrm{g})$ & Resistant & & \\
\hline
\end{tabular}

observations of multi-drug resistance among Lactobacillus spp. have been reported by other researchers ${ }^{15,16}$. Resistance to the commonly used antibiotics suggests that these isolates would be able to withstand the high antibiotic concentrations occasionally observed in the environment and human intestinal tract. Additionally, ingestion of antibiotic often inhibits the residential microflora of the intestinal tract. Therefore administration of antibiotic resistant Lactobacillus will also help to maintain as well as restore the normal intestinal flora.

The Lactobacillus isolates obtained in this study are promising candidates for a safe and practical heavy metal bioremediation from environment and human body. Further investigation is needed to conduct in natural gastro-intestinal conditions to elucidate the exact removal capacity and mechanism. It is also necessary to study the heavy meal bioremediation capacity of these isolates in different physio-chemical conditions to determine the optimum parameters for environmental application.

\section{Acknowledgement}

This study has been funded by the Ministry of Science and Technology, Government of the People's Republic of Bangladesh.

\section{References}

1. Ahmad MK, Islam S, Rahman S, Haque MR and Islam MM. 2010. Heavy Metals in Water, Sediment and Some Fishes of Buriganga River, Bangladesh. Int. J. Environ. Res, 4(2): 321-332.

2. Jaishankar M, Tseten T, Anbalagan N, Mathew BB and Beeregowda KN. 2014. Toxicity, mechanism and health effects of some heavy metals. Interdiscip. Toxicol. 7(2): 60-72.

3. Hemambika B, Hempriya J and VR Kannan. 2010. Comparative assessment of heavy metal removal by immobilized and dead cells: A biosorption approach. Afric J Env Sci Tech. 4(2): 77-83.

4. Claus SP, Guillou H and SE Simatos. 2016. The gut microbiota: a major player in the toxicity of environmental pollutants? Biofilms Microbiomes 2: 16003.
5. Ibrahim F, Halttunen T, Tahvonen R and Salminen S. 2006. Probiotic bacteria as potential detoxification tools: assessing their heavy metal binding isotherms. Can. J. Microbiol. 52: 877-885.

6. Monachese M, Burton JP and G Reid. Bioremediation and Tolerance of Humans to Heavy Metals through Microbial Processes: a Potential Role for Probiotics? 2012. App Env Microbiol. 78(18): 6397-6404.

7. Mishra R, Sinha V, Kannan A and Upreti RK. 2012. Reduction of ChromiumVI by Chromium Resistant Lactobacilli: A Prospective Bacterium for Bioremediation. Toxicol Int. 19(1): 25-30.

8. Syukur S, Yolanda S, Jamsari and Fachrial E. 2015. Isolation, antimicrobial activity and bioremediation of heavy metal Cadmium $(\mathrm{Cd})$ by using lactic acid bacteria from Dadih Origin Lareh Sago Halaban, Payakumbuh, West Sumatera, Indonesia. J. Chem. Pharm. Res. 7(9): 235-241.

9. Bhakta JN, Ohnishi K, Munekage Y, Iwasaki K and Wei MQ. 2012. Characterization of lactic acid bacteria-based probiotics as potential heavy metal sorbents. J. App. Microbiol. 112: 1193-1206.

10. Bergey's Manual of Systematic Bacteriology. 2005. Edited by Garrity GM, Brenner DJ, Krieg NR and Staley JT. Williams and Wilkins, Baltimore, USA.

11. Barry AL and Thornsberry C. 1985. Susceptibility tests. Diffusion test procedures. In: Manual of Clinical Microbiology (Lannette EH, Blows A, Housler WJ and Shdomy HJ), $4^{\text {th }}$ edn, pp 978-979. American Society of Microbiology, Washington, DC.

12. Sabir F, Beyatli Y, Cokmus C and DO Darilmaz. 2010. Assessment of Potential Probiotic Properties of Lactobacillus spp., Lactococcus spp., and Pediococcus spp. Strains Isolated from Kefir. J. Food. Sci. 75(9): 568-573.

13. Seiler C and Berendonk TU. 2012. Heavy metal driven co-selection of antibiotic resistance in soil and water bodies impacted by agriculture and aquaculture. Front. Microbiol. 3: 1-10.

14. Shammi T and S Ahmed. 2014. Heavy Metal Tolerance and Antibiotic resistance of Bacillus sp. isolated from two major rivers in Bangladesh. Bang J Microbiol. 30(1\&2): 17-22.

15. Devirgiliis C, Zinno P and Pero G. 2013. Update on antibiotic resistance in foodborne Lactobacillus and Lactococcus species. Front Microbiol. 4:1-13.

16. Devirgiliis C, Barile S and Perozzi G. 2011. Antibiotic resistance determinants in the interplay between food and gut microbiota. Genes Nutr.6: 275-284. 